\title{
Control Using Lookup Table on Dual Fuel Diesel Engines
}

\author{
Bambang Puguh Manunggal ${ }^{1, a}$, Indriyani ${ }^{1, b}$, and Ignatius R Mardiyanto ${ }^{1, c}$ \\ ${ }^{1}$ Energy Conversion Engineering Department, Bandung State Polytechnic, Jl Gegerkalong Hilir, Bandung, 40559, Indonesia

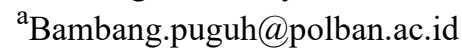 \\ bIndriyani.indriyani@gmail.com \\ 'Ignatius.Mardiyanto@polban ac.id
}

\begin{abstract}
Concerns about the availability of fuel oil reserves and air pollution have encouraged innovation to use of alternative fuels in diesel engines. Single fuel Diesel engines modified with a dual fuel, which is a mixture of diesel and gas. The problem of using mixed fuels is that the flashpoint of natural gas must meet the ignition requirements on diesel engines. The consumption of gas fuel in diesel engines, by the load, can continue to work using dual fuel. In this research, the gas fuel supply to control pattern used of dual-fuel with adjusted to the diesel engine load. The lookup table control method, one of the branches of expert system control, apply to change the valve opening of the gas valve. The efficiency of the control results being slightly lower than if manually controlled but still higher than if the fuel only uses diesel fuel.
\end{abstract}

Keywords-Dual Fuel, Gas Consumption, Lookup Table Control

\section{Introduction}

The use of dual-fuel fuels in diesel engines is one alternative technology that is more environmentally friendly. A book about dual-fuel diesel engines by Gazi A Karim [1], one of the topics is about knocking on dual fuel diesel engines. One of the advantages of natural gas is that natural gas is more environmentally friendly [2]. So it can be expected that the addition of natural gas to diesel engines can reduce emissions.

Dual fuel research on diesel engines for land transportation of large vehicles with the Euro VI standard with the fuel LNG and Diesel, to reduce emissions, has been carried out with results according to these standards [3]. The diesel engine designed to use dual fuel with main gas (LNG) fuel.

Experiments for dual fuel in diesel engines with injection timing settings result in a reduction in specific energy consumption and emissions [4]. The fuel injection angle, the combustion parameters investigation, the parameters causing the increase of NOx in mixing the fuel gas to the search fuel became the topic of problems in the dual-fuel diesel engine, carried out indepth by D.B. Leta et al. [5] to [7]. Previous research on different injection timings has carried out so that the gas injection timing on dual fuel diesel engines is getting better [8]. At low and medium speeds, advancing gas injection timing is not very effective in reducing methane and greenhouse gas emissions. [9] Dual fuel testing at lower to high load to determine the methane gas that does not burn and carbon monoxide mainly occurs in medium loads so that GHG emissions.

Slightly different from research on engines designed with a dual fuel approach, this study used a single fuel diesel engine as a power plant (generator). This research focuses on the experiment of mixing gas fuel on a single fuel engine as an electric generator. Like an electric generator, the diesel engine speed fixed for various load variations without knocking.

In the Yanmar study [11], techniques for introducing gas fuels through airways. The study included gas as a mixing diesel with the combustion air channels. So that air containing gas fuel can be used as a mixture of fuel from the primary fuel, namely, diesel fuel.

From the reference study above that the use of alternative fuels in the form of a mixture of gas and diesel fuel in a diesel engine, apparently not just adding gas fuel and reducing liquid fuel. But presumably, it needs to be assessed when adding fuel gas to keep it operating normally. This paper reviews the addition of natural gas as a mixture of diesel fuel to a single fuel diesel engine. The diesel engine runs as a generator producing electricity with a fixed speed of $1500 \mathrm{rpm}$ equivalent to $50 \mathrm{~Hz}$. 
An alternative diesel engine with a dual fuel system between diesel and gas requires proper mixing arrangements so the machine can operate adequately. This research focuses on the control technique of adding gas fuel to a diesel single fuel diesel engine. For that, the composition of the mixing of gas fuel to avoid knocking needs to assessed. With no knocking criteria, it expected that the addition of gas fuel as a single fuel mixture does not need to make engine modifications. Modifications are only preparing for the technique of entering the gas in the diesel engine.

In this study, a gas fuel supplied by a control system based on engine requirements. Machine needs are taken from the data collection results when the machine is run manually by the operator. The design of control starts with the test data by manually penetrating the fuel gas based on the loading pattern of the electric generator set (Genset). From this manual data, then a program was made to run the Electric Control Unit (ECU). So that the supply of natural gas controlled by the ECU based on the generator's loading pattern. The engine load signal monitored by the ECU, and then the ECU regulates the throttle opening of the gas fuel to enter the engine to prevent knocking of various changes in load current. An attempt to control a dual fuel diesel engine has also been carried out by Rai by using Fuzzy Logic control [12]. In this study, gas control in a dual fuel system uses an expert system with a lookup table.

\section{Research Methodology}

\section{A. Single Fuel Diesel Machine}

The generator used has a capacity of $45 \mathrm{~kW}$ with a nominal rotation of $1500 \mathrm{rpm}$ and an output voltage of 385 volts. The rotation governed using a governing system that controls the input of diesel fuel so that the rotation stays at 1500 rotation per minute. Table 1 below is a table of diesel engine specifications used in this study.

Table 1. Diesel Engine Specifications

\begin{tabular}{|l|l|}
\hline Engine Type: Diesel & Fuel Type: Diesel \\
\hline Type: 4BTA3.9 & Cylinder Diameter: $102 \mathrm{~mm}$ \\
\hline $\begin{array}{l}\text { Number of Cylinder: } 4 \text { cylinder } \\
\text { horizontal }\end{array}$ & $\begin{array}{l}\text { Comparison of Compression } \\
16,5: 1\end{array}$ \\
\hline $\begin{array}{l}\text { Engine Classification: Four Stroke } \\
\text { Diesel }\end{array}$ & Power: $45 \mathrm{KW}$ \\
\hline Firing order: 1.3.4.2 & Cooling Capacity: 7.9 liter \\
\hline Combustion System: Direct & Engine Weight: $329 \mathrm{~kg}$ \\
\hline
\end{tabular}

\begin{tabular}{|l|l|}
\hline Injection & \\
\hline The volume of Cylinder: 3,9 liter & $\begin{array}{l}\text { The size of Stroke: } 9,8 \times 10- \\
4 \mathrm{~m} 3\end{array}$ \\
\hline
\end{tabular}

\section{B. Injection Gas Fuel to Single Fuel Diesel Engine}

In this research, a gas fuel supply system developed as a mixture of liquid fuels, namely diesel fuel in PLTD. The diesel fuel supply system on the diesel engine as a generator is designed based on the load requirements of the generator.

Genset rotation is constant, i.e., the Genset is governed by a governing system to get a $1500 \mathrm{rpm}$ rotation and an output voltage of 385 volts. In other words, the change in load by the governor is followed by a change in diesel fuel consumption so that the rotation will remain constant at $1500 \mathrm{rpm}$ for various load variations. The Genset variation load followed by changes in diesel consumption, changes in power demand followed by fuel consumption as a step to adjust the input power, and then the governor is automatically followed by the action to reduce diesel consumption. And vice versa, if additional fuel reduces, the governor adds diesel to maintain engine speed.

Using the above, gas fuel as a mixture can be done by injecting the gas into the combustion air intake. Figure 1 is a scheme of the design of a gas fuel supply system as a dual-fuel engine.

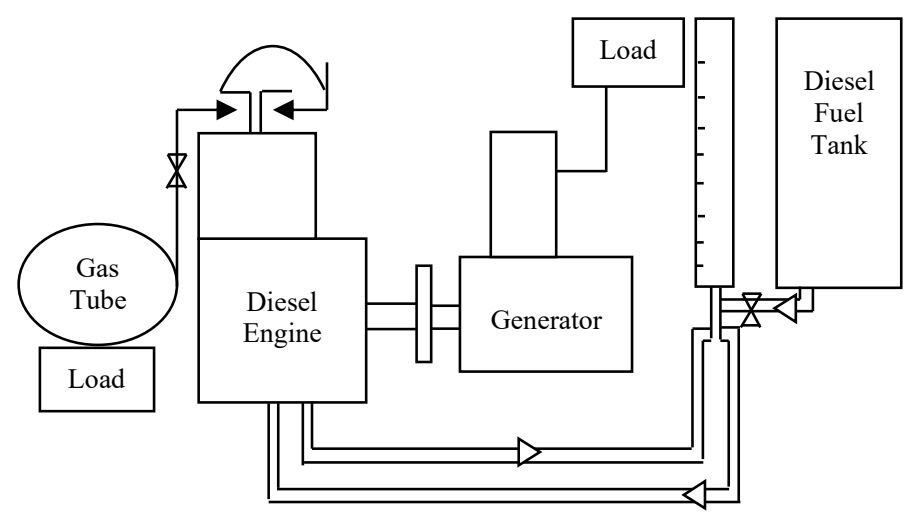

Figure 1. Schematics Diagram for Injection Gas Fuel to Diesel Engine

In this research, a gas fuel supply system made as a mixed fuel, the amount of which based on the engine load. Changes in gas fuel supply due to load variations is carried out with a lookup table control system or expert system. Namely, the control system by looking at load variations, indicated by changes in the load current, to 
adjust the valve openings based on predetermined data. As an example of control, at a load of 5 amperes, the gas fuel valve opening is 1 degree, at a current output of 10 amperes, the valve opening is 3 degrees, and so on.

The load and valve opening data table take from a manual loading experiment. Data collection take by conducting loading experiments by increasing the load on a relatively regular basis. At each increase, the Genset output offset by the addition of gas fuel or the addition of gas fuel valve openings. Adjustment of the addition of the valve opening done manually and the data made into a data record. The data record took when the engine was knocking due to the addition of gas fuel. That data of fuel gas valve opened before the engine knocking at a load value. Then the data record used as an expert system by the lookup table control stored in the data processor.

Control commands are carried out by the data processor. Namely, an order to the actuator open the fuel valve by the value of the load current. The valve opening order is the percentage of the gas fuel valve opening. The figure below illustrates the percentage control system of gas fuel valve openings.

When load variations occur, the current changes recorded on the processor data that has been embedded by the program. Furthermore, the processor works to respond to changes in current and provide a signal to the actuator to change the position of the percentage of the valve opening. With the change in valve opening position, there will be a change in gas fuel supply.

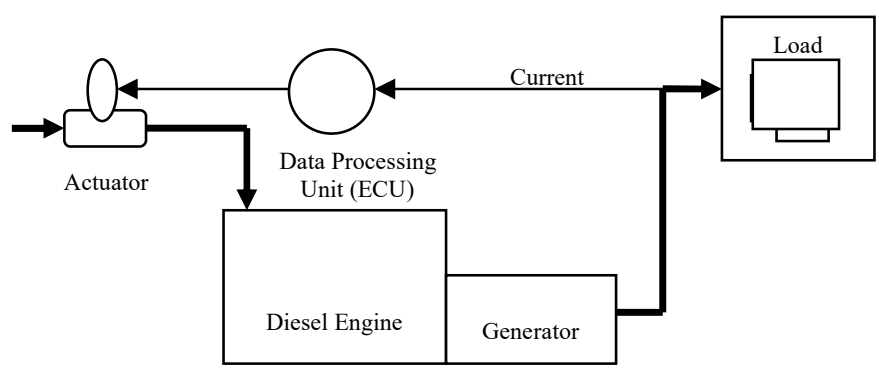

Figure 2. Diagram of a fuel gas control system

\section{Method of Taking Manual Record Data}

The diesel engine as a Genset works at a constant speed. In this study is $1500 \mathrm{rpm}$. Fuel supply supplier operations controlled by the governor based on changes in load from the generator. The diesel fuel increases according to load demand, the balance of input and output power causes the engine speed and voltage to be constant. If the current output rises, the throttle of diesel fuel by the governing system opened.

When the engine operated by using multiple fuels, where some diesel fuel will reduce and replaced with natural gas, then the control opened the gas fuel valve. So, the gas will enter the engine together with air. With increasing fuel consumption, the diesel engine experiences excess fuel so that the diesel supply automatically decreases by itself, and the fuel consumption balanced with the engine load. However, the input supply of natural gas must be control so that there is no detonation when an excess supply of natural gas.

The method of regulating gas fuel done by opening the gas fuel valve slightly in such a way that the engine experiences an unstable condition. In this condition, there are symptoms of knocking in the combustion chamber. This condition shows that there is an excess supply of natural gas so that the gas starts burning before the expected time of combustion. The gas valve opening reduced slowly until the knocking symptoms disappear. In this condition, it is the most significant gas fuel supply at that load. The gas fuel valve opening must be adjusted so that the gas fuel valve opening angle modeling obtained at each output current load.

\section{Results and Discussion}

Genset testing using only diesel fuel has the highest efficiency at a value of $36.4 \%$. The generator control uses the governor to regulate the openings of the diesel fuel valve. The results of controlling the Genset rotation using a single fuel by the diesel fuel are as following Table 2 .

Table 2. Data processing of generator set results with diesel fuel

\begin{tabular}{|c|c|c|c|c|c|c|}
\hline \multirow{2}{*}{$\begin{array}{c}\text { Current } \\
{[\mathrm{A}]}\end{array}$} & $\begin{array}{c}\text { Position } \\
\text { Valve } \\
{\left[\ldots^{\circ}\right]}\end{array}$ & $\begin{array}{c}\text { Fuel } \\
{[\mathrm{ltr} / \mathrm{s}]}\end{array}$ & $\begin{array}{c}\text { Fuel } \\
{[\mathrm{Kg} / \mathrm{s}]}\end{array}$ & $\begin{array}{c}\text { Energy } \\
\text { of Fuel } \\
{[\mathrm{KJ} / \mathrm{s}]}\end{array}$ & $\begin{array}{c}\text { Generator } \\
\text { Power } \\
{[\mathrm{KW}]}\end{array}$ & $\begin{array}{c}\text { Efficien } \\
\text {-cy }[\%]\end{array}$ \\
\hline 0.0 & 0 & $1.1 \mathrm{E}-03$ & $9.1 \mathrm{E}-04$ & 39.2 & 0.0 & 0.0 \\
\hline 13.3 & 10 & $1.0 \mathrm{E}-03$ & $8.7 \mathrm{E}-04$ & 37.5 & 5.1 & 13.6 \\
\hline 20.1 & 15 & $1.2 \mathrm{E}-03$ & $1.0 \mathrm{E}-03$ & 44.6 & 7.7 & 17.4 \\
\hline 32.0 & 24 & $1.3 \mathrm{E}-03$ & $1.1 \mathrm{E}-03$ & 48.8 & 12.3 & 25.2 \\
\hline 38.9 & 29 & $1.5 \mathrm{E}-03$ & $1.3 \mathrm{E}-03$ & 57.3 & 15.0 & 26.2 \\
\hline 49.3 & 38 & $1.6 \mathrm{E}-03$ & $1.3 \mathrm{E}-03$ & 57.9 & 19.0 & 32.8 \\
\hline 62.4 & 48 & $1.8 \mathrm{E}-03$ & $1.5 \mathrm{E}-03$ & 65.9 & 24.0 & 36.4 \\
\hline 70.3 & 54 & $2.0 \mathrm{E}-03$ & $1.7 \mathrm{E}-03$ & 74.9 & 27.1 & 36.2 \\
\hline 81.2 & 63 & $2.4 \mathrm{E}-03$ & $2.0 \mathrm{E}-03$ & 88.1 & 31.2 & 35.5 \\
\hline 94.2 & 72 & $2.7 \mathrm{E}-03$ & $2.4 \mathrm{E}-03$ & 102.0 & 36.3 & 35.5 \\
\hline 98.7 & 76 & $2.9 \mathrm{E}-03$ & $2.5 \mathrm{E}-03$ & 107.8 & 38.0 & 35.3 \\
\hline
\end{tabular}


After the Genset tested using a single fuel, the next test used as dual fuel. The Genset testing with dual fuel done with the following steps.

1. Turn on the generator at zero current output load, with nominal frequency and voltage

2. Adjust the fuel gas until the generator sets are a little unstable, return it to stable condition

3. When the condition responds to stable at that load, then measure the use of diesel fuel up to $50 \mathrm{ml}$ measure the time of consumption of diesel fuel measure the reduction in weight of $\mathrm{CNG}$ fuel

4. Repeat measurements steps 1,2 , and 3 for other loads.

Figure 3 is a gas valve opening actuator device on a dual fuel generator control. The size of the gas valve opening can be adjusted manually by adjusting the valve opening angle.

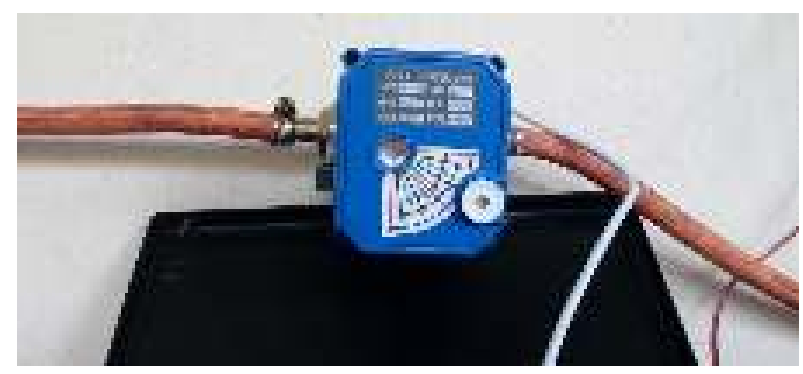

Figure 3. The actuator unitfor valve gas fuel supply

The measurement results are then processed to get the consumption of diesel fuel and gas fuel. From the mixture fuel consumption, the fuel consumption can be dual fuel for every second, in various load conditions. Load power can be calculated based on current, voltage, and load power factors. Also, the valve openings for each load and the double fuel consumption shown in table 3 below.

Table 3. Manually processing data according to the valve gas opened from test results

\begin{tabular}{|c|c|c|c|c|c|c|c|}
\hline \multirow[b]{2}{*}{$\begin{array}{c}\text { Valve } \\
\text { Positi } \\
\text { on } \\
{\left[\ldots{ }^{\circ}\right]}\end{array}$} & \multirow{2}{*}{$\begin{array}{c}\text { Load } \\
\text { Curre } \\
\text { nt } \\
(A)\end{array}$} & \multicolumn{3}{|c|}{ Consumption } & \multirow[b]{2}{*}{$\begin{array}{l}\text { Percenta } \\
\text { ge Gas } \\
\text { per Dual } \\
\text { fuel (\%) }\end{array}$} & \multirow[b]{2}{*}{$\begin{array}{c}\text { Generat } \\
\text { or } \\
\text { Power } \\
{[K W]}\end{array}$} & \multirow[b]{2}{*}{$\begin{array}{c}\text { Efficien } \\
\text { cy [\%] }\end{array}$} \\
\hline & & $\begin{array}{c}\text { Dies } \\
\text { el } \\
{[K J / s} \\
]\end{array}$ & $\begin{array}{c}\mathrm{LN} \\
\mathrm{G} \\
{[K J /} \\
s] \\
\end{array}$ & $\begin{array}{c}\text { Dual } \\
\text { Fuel } \\
{[K J /} \\
s] \\
\end{array}$ & & & \\
\hline 0 & 0.0 & 27.8 & 5.3 & 33.2 & 16 & 0 & 0 \\
\hline 10 & 13.3 & 28.4 & 5.3 & 33.7 & 16 & 5.1 & 15.2 \\
\hline 15 & 20.1 & 31.0 & 5.9 & 36.9 & 16 & 7.7 & 21.0 \\
\hline 24 & 32.0 & 40.9 & 7.4 & 48.3 & 15 & 12.3 & 25.5 \\
\hline 29 & 38.9 & 45.8 & 10.4 & 56.1 & 18 & 15.0 & 26.7 \\
\hline 38 & 49.3 & 46.9 & 10.5 & 57.4 & 18 & 19.0 & 33.1 \\
\hline 48 & 62.4 & 52.5 & 10.8 & 63.3 & 17 & 24.0 & 38.0 \\
\hline
\end{tabular}

\begin{tabular}{|c|c|c|c|c|c|c|c|}
\hline 54 & 70.3 & 62.3 & 11.6 & 73.9 & 16 & 27.1 & 36.6 \\
\hline 63 & 81.2 & 76.1 & 12.4 & 88.4 & 14 & 31.2 & 35.3 \\
\hline 72 & 94.2 & 91.2 & 20.9 & $\begin{array}{c}112 . \\
1\end{array}$ & 19 & 36.3 & 32.4 \\
\hline 76 & 98.7 & $\begin{array}{c}105 . \\
2\end{array}$ & 28.1 & $\begin{array}{c}133 . \\
3\end{array}$ & 21 & 38.0 & 28.5 \\
\hline
\end{tabular}

From Table 3, several graphs of gas fuel consumption in the dual fuel generator system made on the valve opening. Valve openings for loading consumption shown in Figure 4. Use the curve fitting, the relationship of gas fuel consumption in a dual fuel diesel engine to valve openings approximated by the order four deferential equation.

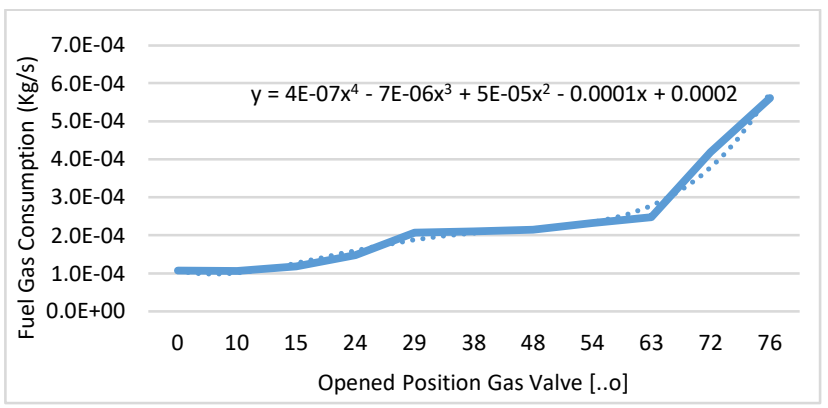

Figure 4. Graph of valve openings (Manual) for fuel consumption

Then, because what desired as a control is the valve opening to the load current, the following is a picture of the relationship of the valve opening to the load current. It can be seen in Figure 5 that the valve opening to the load current approached linearly.

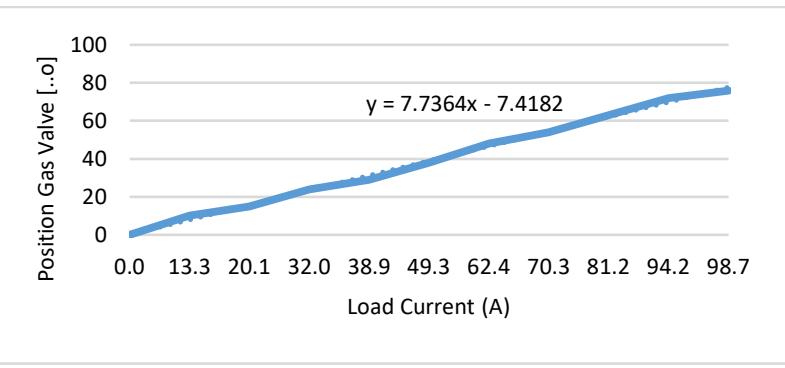

Figure 5. Graph of valve position vs. Load current

From the above test, it shows that manual gas valve opening modeling contributes to fuel consumption and can reduce diesel fuel consumption. From manual testing, it shows that the gas fuel valve openings are directly proportional to the load current on the generator set. Full control of the gas valve openings with lookup table techniques used the relationship between the load 
current and the valve opening, and the frequency of the Genset controlled by using a diesel fuel regulator. The results of the control using the lookup table technique on the gas valve opening and managing the diesel fuel valve opening with governor control, are shown in Table 4.

Table 4. Automatic data processing according to the valve gas opened from the test results

\begin{tabular}{|c|c|c|c|c|c|c|c|}
\hline Valve & Load & \multicolumn{3}{|c|}{ Consumption } & Percenta & Gener & \\
\hline $\begin{array}{c}\text { Positi } \\
\text { on } \\
{[\ldots o]}\end{array}$ & $\begin{array}{c}\text { Current } \\
\text { (A) }\end{array}$ & $\begin{array}{l}\text { Diesel } \\
{[\mathrm{KJ} / \mathrm{s}]}\end{array}$ & $\begin{array}{c}\text { Gas } \\
\mathrm{KJ} / \mathrm{s} \\
]\end{array}$ & $\begin{array}{c}\text { Dual } \\
\text { Fuel } \\
{[\mathrm{KJ} / \mathrm{s}]}\end{array}$ & $\begin{array}{l}\text { ge Gas } \\
\text { per Dual } \\
\text { fuel (\%) }\end{array}$ & $\begin{array}{c}\text { ator } \\
\text { Power } \\
{[\mathrm{KW}]}\end{array}$ & $\begin{array}{l}\text { ency } \\
{[\%]}\end{array}$ \\
\hline 0 & 0 & 27.8 & 0.0 & 27.8 & 0.0 & 0.0 & 0.0 \\
\hline 13.3 & 10 & 28.4 & 5.9 & 34.3 & 17.1 & 5.1 & 15.0 \\
\hline 19.2 & 14 & 28.8 & 7.0 & 35.8 & 19.5 & 7.4 & 20.6 \\
\hline 20.1 & 15 & 30.2 & 7.2 & 37.4 & 19.3 & 7.7 & 20.6 \\
\hline 31.9 & 24 & 40.5 & 9.6 & 50.1 & 19.1 & 12.3 & 24.5 \\
\hline 35.9 & 28 & 44.1 & 9.9 & 54.1 & 18.4 & 13.8 & 25.6 \\
\hline 38.9 & 29 & 45.2 & 10.3 & 55.5 & 18.5 & 15.0 & 27.0 \\
\hline $\begin{array}{l}49.4 \\
\end{array}$ & 38 & 46.1 & 10.4 & 56.5 & 18.4 & 19.0 & 33.6 \\
\hline 62.3 & 48 & 53.9 & 10.6 & 64.5 & 16.4 & 24.0 & 37.2 \\
\hline 70.2 & 54 & 65.5 & 11.5 & 77.0 & 14.9 & 27.0 & 35.1 \\
\hline 81.8 & 63 & 81.7 & 12.6 & 94.2 & 13.3 & 31.5 & 33.4 \\
\hline 94.1 & 72 & 96.3 & 22.2 & 118.5 & $\begin{array}{l}18.7 \\
\end{array}$ & 36.2 & 30.6 \\
\hline 98.7 & 76 & 113.9 & 28.9 & 142.8 & 20.3 & 38.0 & 26.6 \\
\hline
\end{tabular}

From Table 3 and Table 4 in the efficiency column, it shows that using a lookup table control turns out the use of fuel slightly decreases compared to manual control. Lookup table control techniques controlled the opening of the valve gas on the diesel generator set. The control unit operates as a dual fuel generator, and it used as pretty good control.

\section{Conclusion}

Diesel-based the single fuel diesel machine operated using dual fuel with a mixture of the mixed fuels in the form of gas (LNG) theoretically more environmentally friendly. Control of natural gas as a blended fuel done with a lookup table technique, this lookup table control technique is part of the control method with expert system techniques. According to the lookup table control and manual, the manual slightly less efficient, with the highest efficiency value being $38 \%$ in the manual by the operator and automatic control $37.2 \%$, but it still good enough to be used as a simple control device. The automatic for control the Genset with dual fuel is always reasonable when compared to diesel-fueled generators alone, i.e., the highest efficiency value is $36.4 \%$.

\section{Acknowledgment}

Authors would like to thank to the Bandung State Polytechnic for funding this laboratory strengthening study.

\section{References}

[1] Ghazi A Karim, Dual Fuel Diesel Engines, CRC Press, Taylor \& Francis Group, New York, 2015.

[2] B. Ashok, S. Denis Ashok, C. Ramesh Kumar, $L P G$ diesel dual-fuel engine - A critical review, Alexandria Engineering Journal, 2015.

[3] R.J. Vermeulen,Emissions testing of a Euro VI LNGdiesel dual-fuel truck in the Netherlands, Traffic \& Transport, The Netherlands, 3 April 2019.

[4] Hua Zhou, et al., Effects of Injection Timing on Combustion and Emission Performance of Dual-Fuel Diesel Engine under Low to Medium Load Conditions, Energies, $19 \quad$ June 2019 https://doi.org/10.3390/en12122349

[5] D.B.Lata, et al., Analysis of ignition delay period of a dual fuel diesel engine with hydrogen and LPG as secondary fuels, International journal of hydrogen energy 36 , pp 3746 - 3756, 2011.

[6] D.B.Lata, et al., Investigations on the combustion parameters of a dual fuel diesel engine with hydrogen and LPG as secondary fuels, International journal of hydrogen energy 36, pp $13808-13819,2011$.

[7] D.B.Lata, et al., Effect of hydrogen and LPG addition on the efficiency and emissions of a dual fuel diesel engine, International journal of hydrogen energy 37, pp 60846096, 2012.

[8] S Hassan, Z A Zainal, and M A Miskam, Effects of advanced injection timing on performance and emission of a supercharged dual-fuel diesel engine fueled by producer gas from downdraft gasifier, 220 Journal of Scientific \& Industrial Research, Vol. 70, pp. 220-224, March 2011.

[9] AminYousefi,Hongsheng Guo, Madjid Birouk, Effect of diesel injection timing on the combustion of natural gas/diesel dual-fuel engine at low-high load and low-high speed conditions, FUEL, Volume 235, 1 January 2019. https://doi.org/10.1016/j.fuel.2018.08.064

[10] AminYousefi,Hongsheng Guo, Madjid Birouk, Effect of swirl ratio on NG/diesel dual-fuel combustion at low to high engine load conditions, Applied Energy 229, 4 August https://doi.org/10.1016/j.apenergy.2018.08.017

[11] Yanmar Technical Review, A Study of Gas-Diesel Dual Fuel Combustion for Higher Thermal Efficiency and Lower Emissions, 12019. (https://www.yanmar.com/id/technology/technical_review /2019/1001_6.html)

[12]Rai, Adarsh, et al., Fuzzy Logic Based Prediction of Performance and Emission Parameters of LPG-Diesel dual Fuel Engine, SciVerse ScienceDirect, Procedia Engineering 38 280-292. 2012. 